\title{
PROPOSING A NEW METHODOLOGY BASED ON FUZZY LOGIC FOR TUNNELLING RISK ASSESSMENT
}

\author{
Abdolreza YAZDANI-CHAMZINI \\ Young Researchers Club, South Tehran Branch, Islamic Azad University, \\ Tehran, Iran
}

Received 07 Mar 2013; accepted 17 Jul 2013

\begin{abstract}
Tunnels are artificial underground spaces that provide a capacity for particular goals such as storage, underground transportation, mine development, power and water treatment plants, civil defence. This shows that the tunnel construction is a key activity in developing infrastructure projects. In many situations, tunnelling projects find themselves involved in the situations where unexpected conditions threaten the continuity of the project. Such situations can arise from the prior knowledge limited by the underground unknown conditions. Therefore, a risk analysis that can take into account the uncertainties associated with the underground projects is needed to assess the existing risks and prioritize them for further protective measures and decisions in order to reduce, mitigate and/or even eliminate the risks involved in the project. For this reason, this paper proposes a risk assessment model based on the concepts of fuzzy set theory to evaluate risk events during the tunnel construction operations. To show the effectiveness of the proposed model, the results of the model are compared with those of the conventional risk assessment. The results demonstrate that the fuzzy inference system has a great potential to accurately model such problems.
\end{abstract}

Keywords: risk assessment, fuzzy logic, fuzzy risk assessment, tunnelling.

Reference to this paper should be made as follows: Yazdani-Chamzini, A. 2014. Proposing a new methodology based on fuzzy logic for tunnelling risk assessment, Journal of Civil Engineering and Management 20(1): 82-94.

http://dx.doi.org/10.3846/13923730.2013.843583

\section{Introduction}

Nowadays, the world is witnessing an ever-increasing need for tunnels on account of their unique features and potential applications. Tunnel is defined as artificial underground space that provides a high capacity for particular goals like storage, underground transportation, mine development, and civil defence. Hence, tunnel construction plays a critical role in developing infrastructure projects. Tunnel construction imposes risks on all parties involved as well as on those not directly involved in the project (Eskesen et al. 2004). These risks may dramatically influence operation requiring an unexpected time for renovation resulting in major cost and time delays (Fouladgar et al. 2012b). Cases in point, the Jubilee Line Transit Project in London was finished two years late and $£ 1.4$ billion $(67 \%)$ over budget (the budget which was communicated at the time of decision to proceed) and Denmark's Great Belt Link with 54\% over budget (Salvucci 2003). To avoid such problems, managers are obliged to carry out a risk management program. Identification and management of risk is a key to meeting cost and schedule for such projects. Generally, risk ma- nagement in tunnelling helps authorities to make a proper decision on account of the following reasons (Reilly, Brown 2004; Fouladgar et al. 2012b): 1) to reduce the risk to project goals and objectives; 2) to demonstrate that options were comprehensively and rationally evaluated; 3) the process will reveal useful information even if hazards do not occur; 4) to clarify internal project goals, objectives and priorities and focus the project team; and 5) probable ranges of cost and schedule can be estimated.

According to the importance of the problem of risk in tunnelling, different models have been conducted to provide a systematic framework in order to manage the risks involved in tunnel construction (Einstein 1996; Yoo, Kim 2003; Moergeli 2004; Eskesen et al. 2004; Reilly, Brown 2004; Reilly 2005; Huang, Chen 2006; Aye et al. 2006; Richards, Nilsen 2007; Thomas, Banyai 2007; Holicky 2008; Gattinoni et al. 2008; Hong et al. 2009; Zou, Li 2010; Aneziris et al. 2010; Cerić et al. 2011; Fouladgar et al. 2012b; Sousa, Einstein 2012; Yazdani-Chamzini et al. 2013). However, rocks and soils are materials with properties that can change instantly and significantly from one point to the next as well as further compli-

Corresponding author: Abdolreza Yazdani-Chamzini

E-mail: abdalrezaych@gmail.com 
cations may come from uncertainties in the strains that the new facility must withstand during construction and operation (Ghorbani et al. 2012). Therefore, there is an intrinsic risk associated with tunnel construction owing to the limited a priori knowledge of the existing subsurface conditions (Sousa, Einstein 2012). These uncertain conditions can potentially lead to the unwanted consequences during the process of tunnel construction that may adversely affect the project. However, the aforementioned models ignore the inherent uncertainty involved in the process of tunnelling. This may inaccurately reflect the situation of tunnel construction operations. On the other hand, the merit of using new powerful technology is to model a system or sub-system accurately. Consequently, it is necessary to develop the robust methodology that is capable of handling the uncertainty involved in the process of modelling as well as accurately assesses the risks connected with tunnelling.

The merit of using a fuzzy approach is to model the behaviour of a system or sub-system using linguistic labels and fuzzy expressions instead of rigid mathematical rules and equations to be more adapted to the real world cases. Fuzzy logic, first introduced by Zadeh (1965), is a powerful tool to handle the inherent uncertainty and complexity connected with engineering problems. Based on the unique capabilities of fuzzy logic, this technique is widely employed by a large number of researchers to model different aspects of risk management. The advantages of the fuzzy approach in comparison with the traditional methodology are two-fold (Tay, Lim 2006): 1) it simply allows risk evaluation, ranking, and prioritization to be conducted based on experts' knowledge, experiences, and opinions; and 2) it allows the risk evaluation function to be customized based on the nature of a process.

Markowski and Mannan (2009) developed the application of the fuzzy logic for risk assessment of major hazards connected with transportation of flammable substances in long pipelines. Xu et al. (2010) developed a fuzzy synthetic evaluation model for assessing the risk level of a particular critical risk group (CRG) and the overall risk level associated with public-private partnerships (PPP) projects in China. An Imprecise Fuzzy Waste Load Allocation Model (IFWLAM) is developed by Rehana and Mujumdar (2009) for water quality management of a river system subject to uncertainty arising from partial ignorance.

Khazaeni et al. (2012) presented a fuzzy adaptive decision making model for selection of balanced risk allocation which transforms the linguistic principles and experiential expert knowledge into a more usable and systematic quantitative-based analysis by using the fuzzy logic. Dikmen et al. (2007) proposed a fuzzy risk assessment methodology for international construction projects. The proposed methodology uses the influence diagramming method for construction of a risk model and a fuzzy risk assessment approach for estimating a cost overrun risk rating. Khalil et al. (2012) used a combination method based on the Layer of Protection Analy- sis (LOPA) and Fuzzy Logic methodology to prevent or limit industrial accidents.

Nieto-Morote and Ruz-Vila (2011) presented a risk assessment methodology based on the Fuzzy Sets Theory and the Analytic Hierarchy Process (AHP). Ngai and Wat (2005) developed a fuzzy decision support system (FDSS) for the assessment of risk in e-commerce (EC) development. A system for assessing the risk of natural disasters based on employing fuzzy set theory is presented by Karimi and Hüllermeier (2007) to complement the probability theory with an additional dimension of uncertainty. Gürcanli and Müngen (2009) proposed a method for assessment of the risks exposed construction sites using a fuzzy rule-based safety analysis to deal with uncertain and insufficient information.

A new predictive risk assessment model for a hospital information system (HIS) was developed by Yucel et al. (2012) to estimate risk before the implementation of new HIS. Wulan and Petrovic (2012) proposed a fuzzy logic based system for risk analysis and evaluation within enterprise collaborations. Shahriar et al. (2012) developed a fuzzy based bow-tie analysis to analyse the risk of oil and gas pipelines. Alidoosti et al. (2012) proposed a fuzzy inference system for the risk assessment of critical asset. A fuzzy risk assessment approach for occupational hazards in the construction industry is presented by Liu and Tsai (2012). Yazdani et al. (2011) developed a framework based on fuzzy logic to analyse the risk of critical infrastructures. Jamshidi et al. (2013) developed an application of the fuzzy logic for modelling the uncertainty involved in the problem of pipeline risk assessment. Razani et al. (2013) used fuzzy inference system (FIS) to predict the roof fall rate in underground mining in order to control, mitigate, and/or even eliminate the risks imposed by underground projects. It is clear that fuzzy logic has demonstrated its worth as a practical engineering and problem-solving tool.

The main aim of this paper is to propose a new methodology based on fuzzy logic to provide an organized and systematic framework for identifying and analysing the significance of potential events associated with tunnel construction. The proposed method incorporates fuzzy concepts into a conventional risk assessment framework. This technique can help authorities to model the risks more accurately and reliably. To valid the proposed model, a real case study is illustrated and the conclusions derived from the model are compared with the outcome obtained by the conventional method.

\section{Traditional risk assessment}

Risk assessment techniques are central to gaining an understanding of what is most uncertain about a project, and they are the foundation for risk management (Kendrick 2003). A wide spectrum of methods is developed to model the risks imposed by projects. Probability-impact function, a branch of the traditional risk assessment methods, is one of the most popular techniques used for assessing the level of the risks. Based on the basic con- 
cepts of the traditional risk assessment, the risk is defined as a function of probability and impact of different accident scenarios (Heldman et al. 2007). This approach applies a risk matrix, well-known as probability-impact (P-I) matrix, to assess the level of risk for different scenarios. The P-I matrix combines the probability of an event with its consequence into an output linguistic risk level. The impact component investigates the potential effect of the risk on a project objective such as schedule, cost, quality or performance; whereas, the probability component investigates the likelihood that each specific risk will occur (Nieto-Morote, Ruz-Vila 2011).

The P-I matrix analysis is a strong tool for identifying and eliminating potential failures to improve the level of safety and reliability of systems or processes. This method provides information for authorities to make a strategic decision.

A typical P-I matrix for risk assessment in tunnel construction is shown in Figure 1.

According to Figure 1, the probability is assigned by numbers such as $1,2,3,4$, and 5 corresponding to a linguistic scale: improbable (IM), remote (R), occasional $(\mathrm{O})$, probable $(\mathrm{P})$, and frequent $(\mathrm{F})$, respectively. Also, Figure 1 depicts a similar scale for consequence categories. Consequence is determined by numbers such as

\begin{tabular}{|c|c|c|c|c|c|c|}
\hline & \multirow{2}{*}{$R=P \times I$} & \multicolumn{5}{|c|}{ Probability } \\
\hline & & Improbable & Remote & Occasional & Probable & Frequent \\
\hline \multirow{5}{*}{ 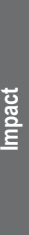 } & Negligible & 1 & 2 & 3 & 4 & 5 \\
\hline & Minor & 2 & 4 & 6 & 8 & 10 \\
\hline & Major & 3 & 6 & 9 & 12 & 15 \\
\hline & Critical & 4 & 8 & 12 & 16 & 20 \\
\hline & Catastrophic & 5 & 10 & 15 & 20 & 25 \\
\hline
\end{tabular}

Fig. 1. P-I risk matrix (Parker 2005)

$1,2,3,4$, and 5 corresponding to negligible $(\mathrm{N})$, minor (M), major (MA), critical (C), and catastrophic (CA), respectively. Output risk level is linguistically denoted as intolerable (INT), significant (S), substantial (SU), tolerable (T), and insignificant (IN). As an illustration, for a typical case in the process of tunnel construction, assume that collapse is a relatively common accident. Therefore, the occurrence probability to this accident can be probable. Whereas, its consequences are definitely serious and its importance to tunnel construction is critical (impact index is critical). The scales for probability, impact, and risk levels are given in Tables 1-3.

In the system of the P-I matrix, the risk index of occurrence is the product of the probability and impact ra-

Table 1. Definition of probability levels

\begin{tabular}{llccc}
\hline \multicolumn{1}{c}{ Linguistic term } & \multicolumn{1}{c}{ Definition } & Crisp rating & Fuzzy rating & Universe of discourse (X) \\
\hline Improbable (IM) & So unlikely event, it may not be experienced & 1 & $1<\mathrm{P} \leq 2.5$ & $\mathrm{X}_{\mathrm{P}} €(1.5)$ \\
\hline Remote (R) & Unlikely to occur during lifetime & 2 & $1 \leq \mathrm{P} \leq 3.5$ & $1.5 \leq \mathrm{P} \leq 4.5$ \\
\hline Occasional (O) & Likely to occur during lifetime & 3 & $2.5 \leq \mathrm{P}<5$ \\
\hline Probable (P) & May occur several times & 4 & $3.5 \leq \mathrm{P} \leq 5$ \\
\hline Frequent (F) & Will occur frequently & 5 & \\
\hline
\end{tabular}

Table 2. Definition of impact levels

\begin{tabular}{lllcc}
\hline \multicolumn{1}{c}{ Linguistic term } & \multicolumn{1}{c}{ Definition } & Crisp rating & Fuzzy rating & $\begin{array}{c}\text { Universe of } \\
\text { discourse }(\mathrm{X})\end{array}$ \\
\hline Negligible $(\mathrm{N})$ & Highly have no impact on the process of tunnelling & 1 & $1<\mathrm{I} \leq 2.5$ & $\mathrm{X}_{\mathrm{I}} €(1.5)$ \\
\hline Minor $(\mathrm{M})$ & Have no critical impact on the process of tunnelling & 2 & $1 \leq \mathrm{I} \leq 3.5$ \\
\hline Major (MA) & Have no substantial impact on the process of tunnelling & 3 & $1.5 \leq \mathrm{I} \leq 4.5$ \\
\hline Critical (C) & Have certain impact on the performance of tunnelling & 4 & $2.5 \leq \mathrm{I}<5$ \\
\hline Catastrophic $(\mathrm{CA})$ & Have highly impact on the performance of tunnelling & 5 & $3.5 \leq \mathrm{I} \leq 5$ \\
\hline
\end{tabular}

Table 3. Definition of risk levels (Parker 2005; Alidoosti et al. 2012)

\begin{tabular}{llcccc}
\hline $\begin{array}{c}\text { Linguistic } \\
\text { term }\end{array}$ & \multicolumn{1}{c}{ Definition } & Response & $\begin{array}{c}\text { Crisp rating } \\
(R=P \times I)\end{array}$ & $\begin{array}{c}\text { Fuzzy } \\
\text { rating }\end{array}$ & $\begin{array}{c}\text { Universe of } \\
\text { discourse }(\mathrm{X})\end{array}$ \\
\hline Insignificant (IN) & Risk is tolerable without any mitigation & Monitor & $(1-4)$ & $0 \leq \mathrm{R} \leq 2.5$ & $\mathrm{X}_{\mathrm{R}(\mathrm{fuzz})} \in(0.5)$ \\
\hline Tolerable (T) & Some partial mitigation may be needed & Regular attention & $(5-8)$ & $0 \leq \mathrm{R} \leq 3$ & $\mathrm{X}_{\mathrm{R}(\mathrm{Crisp})} \in(1.25)$ \\
\hline Substantial (SU) & Mitigation may be needed & Early attention & $(9-12)$ & $1 \leq \mathrm{R} \leq 4$ \\
\hline Significant (S) & Mitigation should be implemented to reduce risk & Unacceptable & $(13-16)$ & $2 \leq \mathrm{R}<5$ \\
\hline Intolerable (INT) & Mitigation that reduces risk must be implemented & Unacceptable & $(17-25)$ & $3 \leq \mathrm{R} \leq 5$ \\
\hline
\end{tabular}


tings (Merna, Al-Thani 2005). This relationship is mathematically defined as follows (Fouladgar et al. 2012b):

$$
R=P \times I,
$$

where $R$ represents the risk index, $P$ represents probability of occurrence and $I$ represents impact of occurrence. The values for $P$ and $I$ are obtained by using the values scaled given in Tables 1 and 2. For example, consider a potential event having value of 2 and 4 for its $P$ and $I$ ratings; it will have a total $R$ of $8(R=2 \times 4=8)$. Values of the $R$ can range from 1 to 25 , in which 1 expresses the smallest risk and 25 addresses the largest. The risks with lower probability and impact are a less serious hazard to project goals than the risks with higher probability and impact (Fouladgar et al. 2012b). This value helps authorities to rank the order of concerns in the process of designing and constructing. This means that for a relatively high $R$, the authorities must fulfil a proper reaction strategy to reduce or eliminate the risks involved in project.

The traditional approach appears to have a number of advantages owing to its unique capabilities. However, there are some shortcomings that are mostly connected with the uncertainty involved in real-world problems. A drastic remedy for such problems is to take into account the concepts of fuzzy logic in the process of the risk assessment.

\section{Proposed methodology}

The handling of the uncertainty involved in the process of project risk management reflects all the available information about risks under consideration. The modelling of the uncertainty leads to a comprehensive analysis on the project risks; as a result, the potential events can be predicted with high accuracy. This is due to the fact that the uncertainties of risk events may be attributed to the randomness inherent in nature and to the lack of sufficient data related to the chances of their occurrence and potential consequences (Beriha et al. 2012). The experts with a high experience in the field of risk analysis can provide a valuable opinion to model the existing uncertainty. However, it is difficult task for the expert team to quantify their valuable knowledge in order to estimate the uncertainty. The fuzzy set theory is a powerful mathematical tool that uses linguistic terms to model the uncertainty resulted from the complexity of systems or sub-systems. Fuzzy logic has the ability to express the ambiguity of human thinking and translate expert knowledge into computable numerical data (Yazdani-Chamzini et al. 2012).

Therefore, the fuzzy logic is used to propose a systematic and standard methodology for handling the uncertainty. Schematic diagram of the proposed model is depicted in Figure 2.

Compared with the P-I risk matrix, the proposed model replaces the risk index with a fuzzy risk assessment function. From Figure 2, it is clear that a fuzzy inference system is applied in the framework of the fuzzy risk assessment to replace the product function used in the traditional P-I matrix.

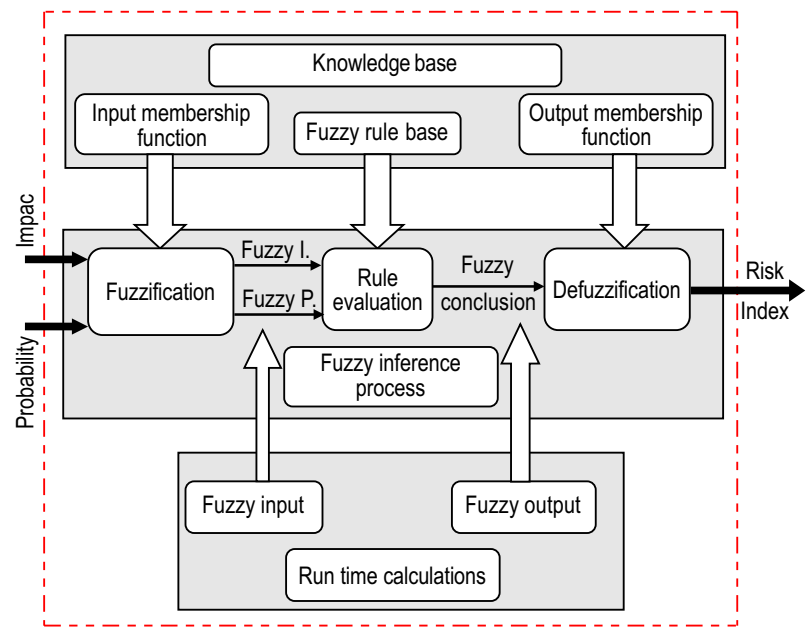

Fig. 2. Overall view of the fuzzy risk assessment system

\section{Fuzzy set theory}

The main idea of the fuzzy set theory is to model the complex structure of science and engineering problems more reliability, surely, and accurately. Instead of determining the exact boundary as in an ordinary set, a fuzzy set allows no sharply defined boundaries because of the generalization of a characteristic function to a membership function (Gupta et al. 1988). This technique is a system based on knowledge (expert system) that is widely used to handle the inherent uncertainty involved in real-life problems (Lashgari et al. 2011, 2012; Fouladgar et al. 2011, 2012a, c, d; Yazdani-Chamzini, Yakhchali 2012).

\section{Fuzzy inference system}

The fuzzy inference system is a rule-based system built in the form of inference if-then rules (Wang 1997). Fuzzy inference is the process of mapping from a given input set to an output set using fuzzy logic (Elsayed 2009). The process of fuzzy inference involves fuzzification of crisp input by defining the membership function, fuzzy logic operators, and IF-THEN rules (Beriha et al. 2012).

Several fuzzy inference systems have been developed to model the linear and nonlinear behaviour of systems, including the Mamdani, the Takagi-Sugeno-Kang (TSK), the Tsukamoto and the Singleton fuzzy models. The differences between these fuzzy inference systems lie in the consequents of their rules, and thus, aggregation and defuzzification procedures differ accordingly (Ghasemi, Ataei 2013).

The Mamdani fuzzy model is one of the most popular mechanisms in fuzzy logic for modelling the problems facing with complexity and uncertainty. The Mamdani fuzzy logic system has many attractive features (Wang 1994): 1) it is suitable for engineering systems because its inputs and outputs are real-valued variables; 2 ) it provides a natural framework to incorporate fuzzy IF-THEN rules from human experts; and 3) there is much freedom in the choices of fuzzifier, fuzzy inference engine, and 
defuzzifier, so that we may obtain the most suitable fuzzy logic system for a particular problem. The general "ifthen" rule structure of the Mamdani algorithm is of the following form (Jamshidi et al. 2013):

$$
\begin{aligned}
& R^{i}=\text { If } x_{1} \text { is } F_{1}^{i} \text { and } \ldots x_{n} \text { is } F_{n}^{i} \text { Then } y \text { is } G^{i} \\
& \text { (for } i=1,2, \ldots K \text { ), }
\end{aligned}
$$

where: $\mathrm{K}$ is total number of fuzzy rule; $x_{n}$ and $G^{i}$ are linguistic values defined by fuzzy sets on the universes of discourse. The If-part of the rule is called the antecedent comprising the inputs, whereas the Then-part of the rule is known as the consequent including the output. The aggregated output for the $\mathrm{K}$ rules is:

$$
\begin{aligned}
& \mu_{G^{i}\left(y_{i}\right)}=\max \left\{\min _{i}\left[\mu_{F_{1}^{i}}\left(x_{1}\right), \mu_{F_{2}^{i}}\left(x_{2}\right), \ldots, \mu_{F_{n}^{i}}\left(x_{n}\right)\right]\right\}, \\
& i=1,2, \ldots K .
\end{aligned}
$$

A typical fuzzy inference system is depicted in Figure 3. From the figure, it can be seen that a fuzzy inference system consists of four main parts: (1) fuzzification; (2) knowledge base; (3) inference engine; and (4) defuzzification.

These parts are explained as follows:

Fuzzification: in the first part, the crisp input is transferred into a linguistic variable (fuzzy value) using the membership functions built in the fuzzy data base. The fuzzification converts the precise information into the form of imprecise information like "very low", "low", "medium", "high", "very high", etc. with a degree of membership. Generally, the value belongs to the closed interval 0 to 1 , where 1 represents full membership and 0 expresses non-membership. In this study, the Gaussian MF is adopted to represent each linguistic term on account of the following reasons (Masters 1995; Xie 2003; Sumathi, Paneerselvam 2010; MathWorks 2012; Alidoosti et al. 2012): 1) this function exhibits properties that are mathematically and computationally tractable; 2 ) this function is a continuously differentiable function and has the advantage of being smooth and nonzero at all points; and 3) this function is smooth and concise. Probability of occurrence and the impact are represented by fuzzy sets whose ranges are selected to coincide with the indicative frequency and severity ranges shown in Tables 1 and 2, respectively. For a better understanding, membership functions connected with the input parameters are schematically depicted in Figures 4 and 5. The fuzzy risk assessment index is considered as output pa-

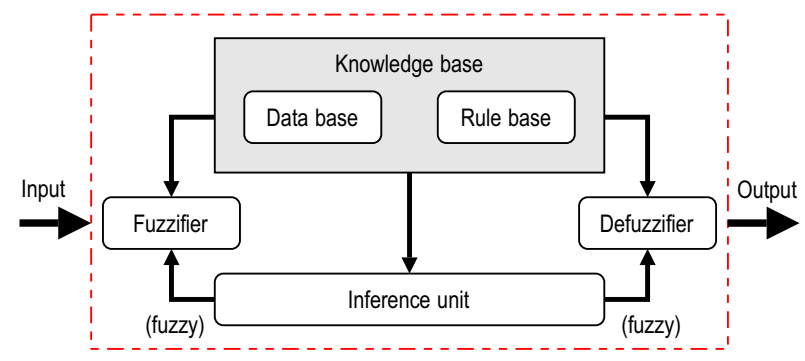

Fig. 3. Structure of FIS rameter varying from 0 to 5 . In this paper, risk is divided into five equal partitions as depicted in Figure 6. Risks are represented by fuzzy sets whose ranges are coincided with the linguistic terms given in Table 3. By using an appropriate conversion scale, the linguistic terms must be transformed into fuzzy ratings. One of the key points in fuzzy modelling is the definition of fuzzy numbers which represent vague concepts and imprecise terms expressed in a natural language (Nieto-Morote, Ruz-Vila 2011).

In the present work, the fuzzification decomposes system variables, including probability $(\mathrm{P})$, severity of impacts $(\mathrm{C})$ and risk categories (R), with crisp numbers and maps the crisp numbers into fuzzy sets. The structure of FIS constructed in this paper is presented in Figure 7.

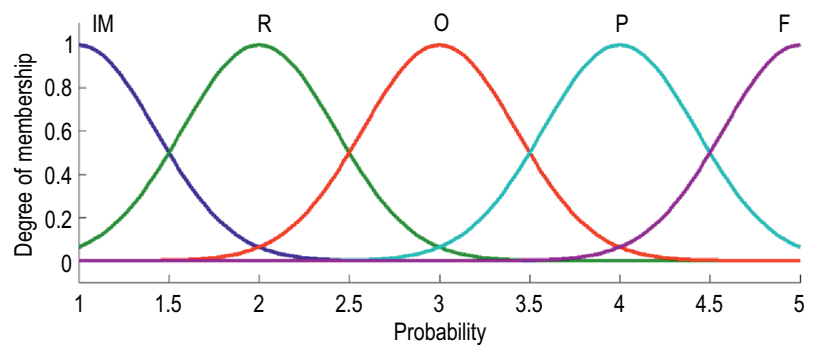

Fig. 4. Membership function for probability of occurrence

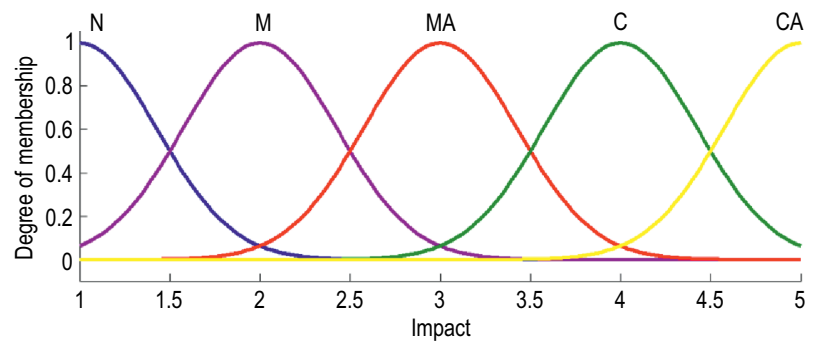

Fig. 5. Membership function for impact levels

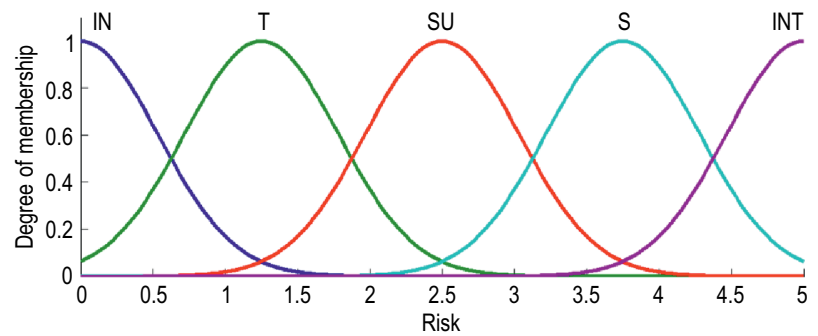

Fig. 6. Membership function for risk

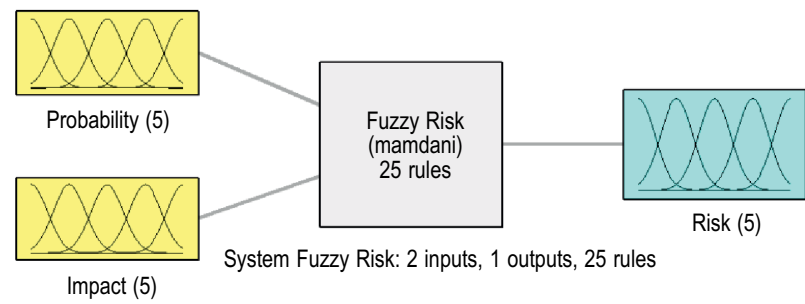

Fig. 7. Structure of the fuzzy model constructed 
In order to construct the fuzzy model, a number of the fuzzy if-then rules are generated to fulfil the reasoning associated with the input and output parameters. Tables 1 and 2 present the membership functions of the two input parameters employed in the process of risk management as illustrated in the next section.

Knowledge base: The membership functions resulted from the previous stage is used to generate the fuzzy if-then rules. These rules form the knowledge base as a set of the rules extracted from experts. Such rules are usually more conveniently formulated in linguistic terms than in numerical terms, and they are often expressed as "If-Then" rules which are easily implemented by fuzzy conditional statements (Chin et al. 2008). The fuzzy inference process uses min-max inference to calculate the rule conclusions based on the system input values (Zadeh 1992). The truth value of a rule is derived from the conjunction. This means that the true value is obtained from minimum degree of membership of the rule antecedents. Thus the truth-value of the rule is taken to be the smallest degree of truth of the rule antecedents (Pillay, Wang 2003). Then, this truth value is applied to all consequences of the rule. If any fuzzy output is a consequence of more than one rule, then output is set to the highest (maximum) truth value of all the rules that include it as a consequence (Chin et al. 2008). The result of the rule evaluation is a set of fuzzy conclusions that reflect the effects of all the rules whose truth-values are greater than zero (Pillay, Wang 2003).

An important contribution of the fuzzy inference system is to provide a systematic procedure for transforming a knowledge map into non-linear mapping (Beriha et al. 2012). A fuzzy IF-THEN rule is an IF-THEN statement in which some linguistic labels are characterized by membership functions. The number of rules depends on the type of problem. In this study, according to the category of the two input parameters and using the logical AND operation, the total number of rules in the knowledge base is equal to 25 . The rules are designed to follow the logic of the risk evaluator. These rules are developed on the basis of the experts' opinion and the available information derived from safety analysis. These rules are deliberately constructed as listed in Figure 8.

Inference engine: the inference engine, by means of a knowledge base, maps input fuzzy sets into fuzzy output sets. For achieving the aim, the inference engine combines the fuzzy if-then rules generated by expert's knowledge.

Fuzzy inferences of the groups are assigned through grades of membership functions of two components. An inference engine is a computer program that simulates the outputs of the fuzzy inference system by deriving answers from the knowledge base. This engine uses the if-then rules to formulate new conclusions. In order to provide a better understanding of the constructed model, the if-then rules are schematically depicted in Figure 9.

The relationships between input and output parameters can be better understood by a three-dimensional plot.

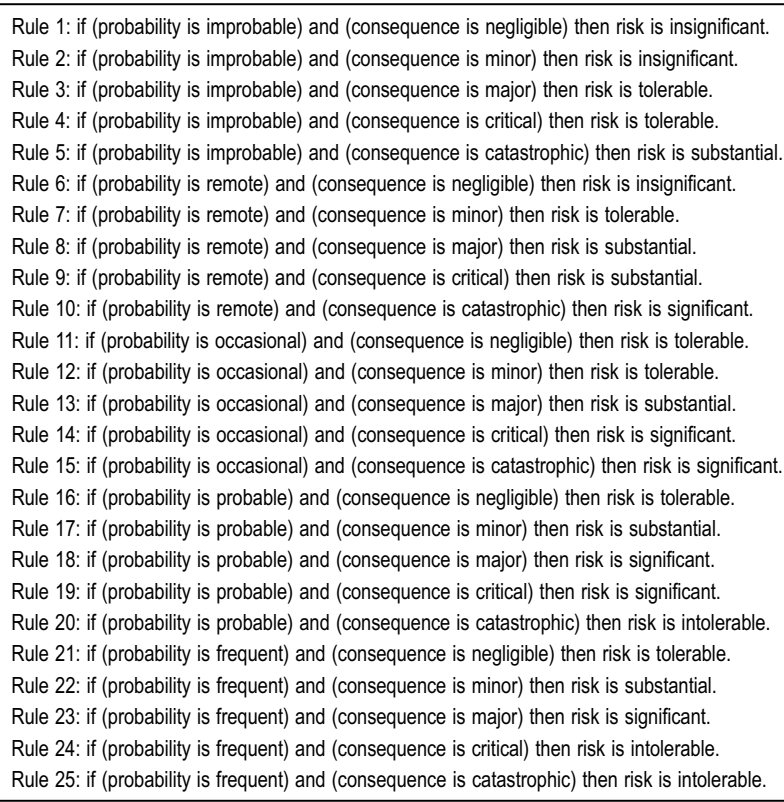

Rule 1: if (probability is improbable) and (consequence is negligible) then risk is insignificant Rule 2: if (probability is improbable) and (consequence is minor) then risk is insignificant. Rule 3: if (probability is improbable) and (consequence is major) then risk is tolerable. Rule 4: if (probability is improbable) and (consequence is critical) then risk is tolerable. Rule 5: if (probability is improbable) and (consequence is catastrophic) then risk is substantial. Rule 6: if (probability is remote) and (consequence is negligible) then risk is insignificant. Rule 7: if (probability is remote) and (consequence is minor) then risk is tolerable. Rule 8: if (probability is remote) and (consequence is major) then risk is substantial. Rule 9: if (probability is remote) and (consequence is critical) then risk is substantial. Rule 10: if (probability is remote) and (consequence is catastrophic) then risk is significant. Rule 11: if (probability is occasional) and (consequence is negligible) then risk is tolerable. Rule 12: if (probability is occasional) and (consequence is minor) then risk is tolerable. Rule 13: if (probability is occasional) and (consequence is major) then risk is substantial. Rule 14: if (probability is occasional) and (consequence is critical) then risk is significant. Rule 15: if (probability is occasional) and (consequence is catastrophic) then risk is significant. Rule 16: if (probability is probable) and (consequence is negligible) then risk is tolerable. Rule 17: if (probability is probable) and (consequence is minor) then risk is substantial. Rule 18: if (probability is probable) and (consequence is major) then risk is significant. Rule 19: if (probability is probable) and (consequence is critical) then risk is significant. Rule 20: if (probability is probable) and (consequence is catastrophic) then risk is intolerable. Rule 21: if (probability is frequent) and (consequence is negligible) then risk is tolerable. Rule 22: if (probability is frequent) and (consequence is minor) then risk is substantial. Rule 23: if (probability is frequent) and (consequence is major) then risk is significant. Rule 24: if (probability is frequent) and (consequence is critical) then risk is intolerable. Rule 25: if (probability is frequent) and (consequence is catastrophic) then risk is intolerable.

Fig. 8. List of the fuzzy if-then rules

This plot represents the mapping from two input parameters (i.e. probability and impact) to one output (i.e. risk). The plot is well-known as risk surface and is applied for risk assessment. This plot shows different regions of risk depend on the value of the input parameters. Figure 10 shows the resulting control surfaces of the fuzzy inputs $\mathrm{P}$ and $\mathrm{I}$ as well as the fuzzy output risk.

Defuzzification: the ultimate step in approximate reasoning is defuzzification. This step contains the process of the replacement of a fuzzy value with a crisp output, comprising a procedure of weighting and averaging the outputs from all of the individual fuzzy rules. There are six methods for defuzzification as follows (Wong, Monaco 1995):

1) centroid average (CA);

2) centre of gravity (COG);

3) maximum centre average (MCA);

4) mean of maximum (MOM);

5) smallest of maximum (SOM);

6) largest of maximum (LOM).

In this paper, the centre of gravity (COG), one of the most popular methods for defuzzifying fuzzy output functions, is selected on account of its simple computations and plausible intuitions. The COG is defined by the following equation:

$$
Z^{*}=\frac{\int \mu_{i}(x) x d x}{\int \mu_{i}(x) d x},
$$

where: $x$ is the output variable; $Z^{*}$ is the defuzzified output; and $\mu_{i}(x)$ is the aggregated membership function. The defuzzification process creates a crisp value from the fuzzy sets to reflect the riskiness of the design; so that, the reaction strategies can be ranked to mitigate the level of the existing risks. 


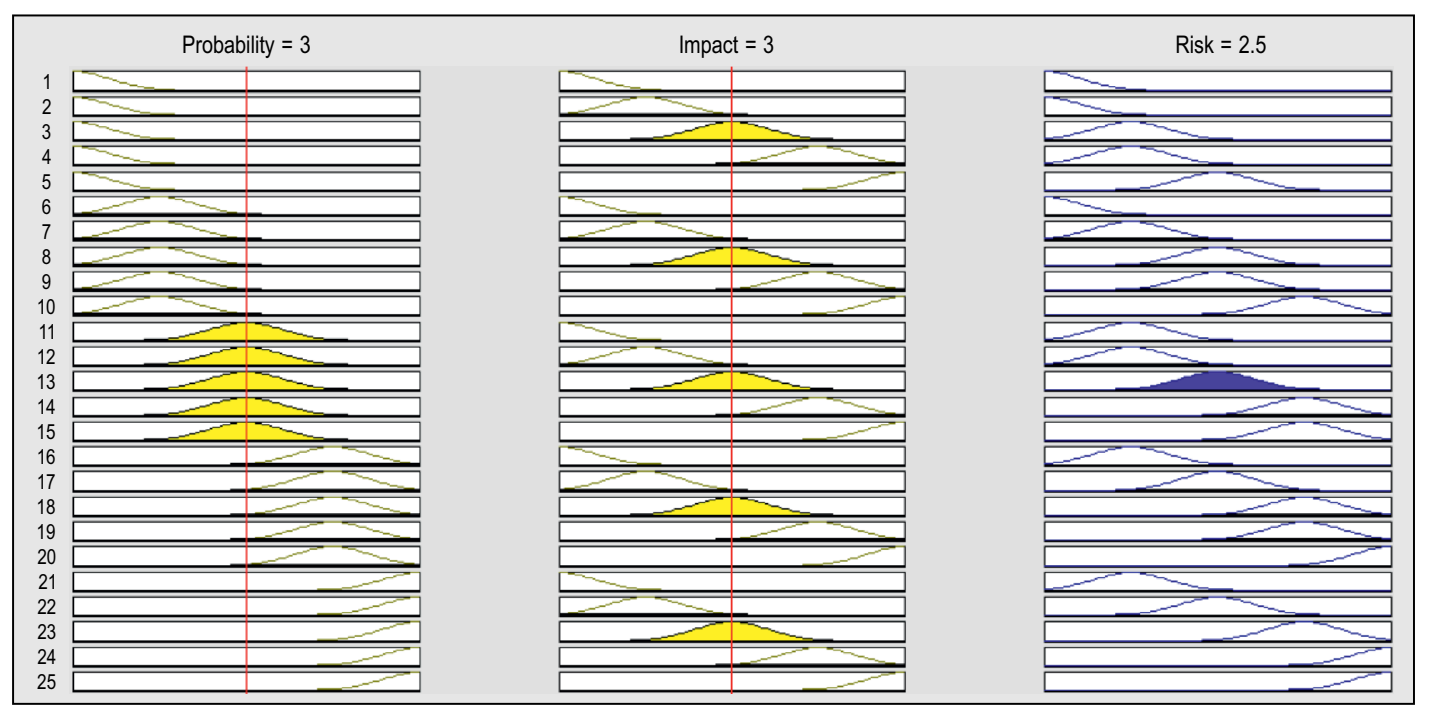

Fig. 9. Sample of rules

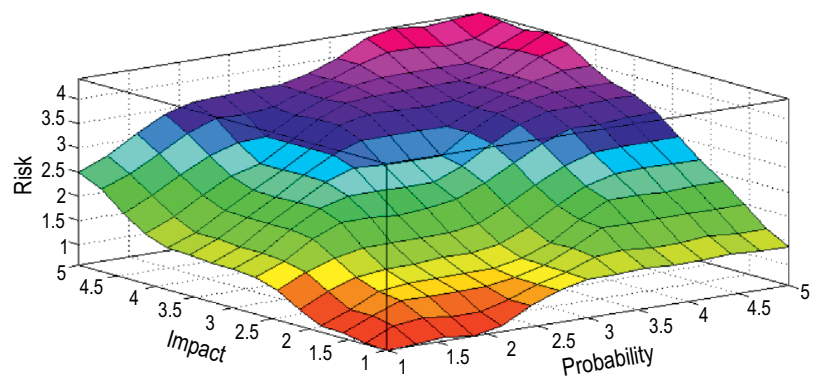

Fig. 10. Control surfaces of the inputs

\section{Case study}

A case study is presented to demonstrate the potential application of the proposed model for assessing the risks involved in the tunnel construction projects. For achieving the aim, the proposed model is used to assess and prioritize the risks in the Zagros long tunnel. This project is under construction in sedimentary rock. It is one of the most important water transfer projects in central Iran that is planned to transfer water from the high elevations in Zagross Mountains to dry plains of Central Iran. Lot \#2 of the project, a $26 \mathrm{~km}$ long tunnel with an average depth of $400 \mathrm{~m}$, is currently under construction using a double shield (DS) TBM (Hamidi et al. 2010). The tunnel is driven in a variety of geological formations, including Pabdeh (PEPd), Gurpi (KGu) and Ilam (Ki) (Sahel Consulting Eng. 2007). The description of anticipated geological and petro-logical condition along the tunnel is shown in Figure 11. The tunnel passes through several formations with rock mass conditions varying from weak to good, with RMR ranging from 20 to 60 . The encountered geological conditions required TBM operation to change frequently from hard rock to soft, dry to flowing, sticky to nonsticky ground (and vice versa), more often than expected (Hamidi et al. 2010).

A tunnelling project is constructed from several major phases that these phases should be clearly analysed to identify the risks in order to make a decision for min- imizing the level of risks (Fouladgar et al. 2012b). For achieving the aim, both project-specific risks arise from the internal environment and general risks imposed by the external environment must be considered to identify all the risks that a tunnel construction project may encounter. Each of the internal and external environments may be a potential source of miscellaneous risks.

One of the simplest methods of identifying risk is checklist analysis. In this paper, a checklist analysis is conducted to understand which risks are involved in the case study illustrated. Therefore, risk assessment is made by using the checklists filled by a team of 7 experts with a minimum experience of four years in field of safety analysis.

Hence, an in-depth analysis of the tunnel construction process made it possible to identify forty-seven major risks associated with tunnelling as listed in Table 4. From Table 4, it can be seen that the project risks are divided into the four groups, twelve categories and risk events are located in the lowest level.

To get information on the existing risks, a questionnaire was designed. Then, the questionnaire was submitted to the safety professionals and the responses were gathered. For each type of the potential events listed in Table 4, the level of probability for each risk and its impact on each objective based on the values given in Tables 1 and 2 are determined by expert team including seven assessors with a high degree of knowledge in the area of risk management. The expert team prioritizes the potential events in terms of $\mathrm{P}$ and I; so that, an event with high risk is located at the top priority. The team members discussed the case until they reached a consensus. Therefore, risk levels are derived from these numerical values as presented in Table 5 . In order to valid the proposed model; the outputs are compared with those of the conventional risk assessment. Based on the basic concepts of the conventional risk assessment, the relative importance of the risks is resulted from the product of the probability and impacts. To achieve the aim, the evaluator team employs the crisp ratings given in Table 1 and 2 to calculate the level of the risks in the form of consensual value. 

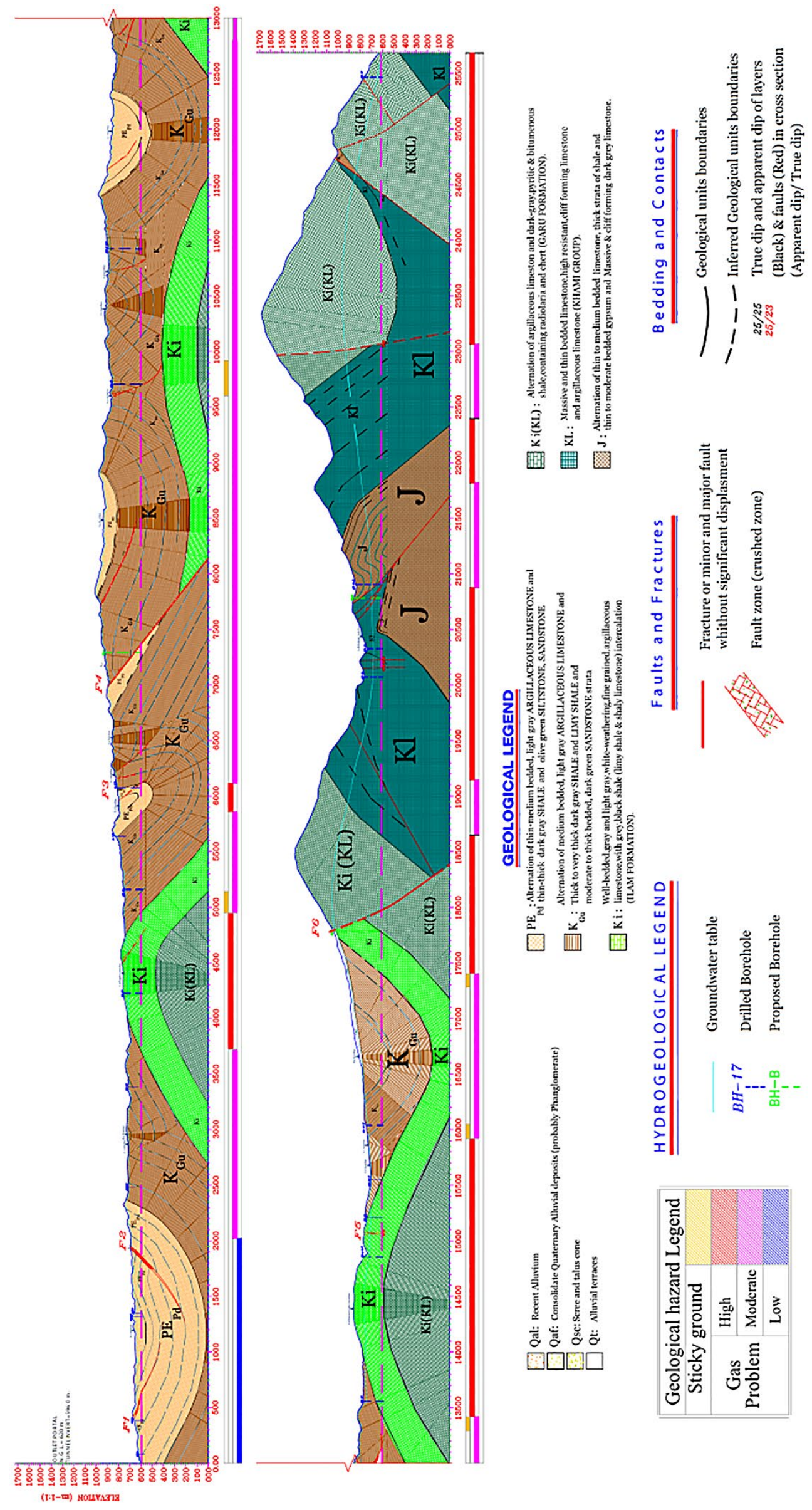

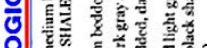

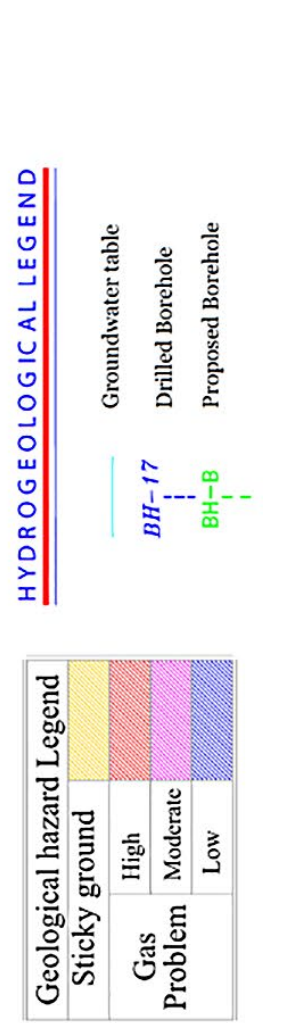

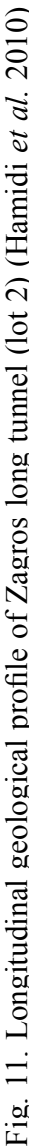


Table 4. List of the risks identified

\begin{tabular}{|c|c|c|}
\hline Risk group & Risk categories & Risk events \\
\hline \multirow{10}{*}{ 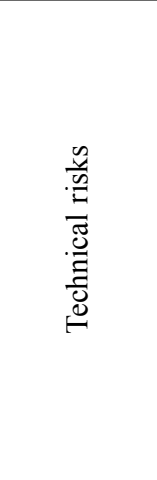 } & \multirow{4}{*}{ Planning risk } & (R1) Land acquisition problem \\
\hline & & (R2) Difficulty in cooperation with related government departments \\
\hline & & (R3) Public opposition \\
\hline & & (R4) Unscientific planning of tunnel construction \\
\hline & \multirow{6}{*}{ Design risk } & (R5) Inadequate design specification and documentation \\
\hline & & (R6) Over break \\
\hline & & (R7) Inaccurate survey data \\
\hline & & (R8) Design mistakes \\
\hline & & (R9) Lack of experienced designers \\
\hline & & (R10) Conflict designs on interface between adjacent areas \\
\hline \multirow{18}{*}{ 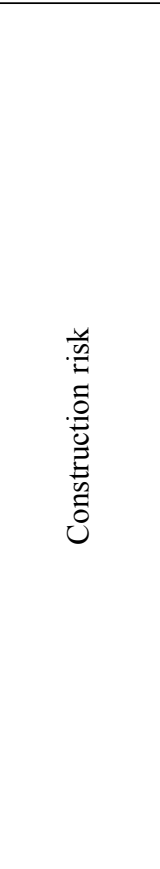 } & \multirow{5}{*}{ Geological risk } & (R11) Water inflow \\
\hline & & (R12) Tunnel walls instability \\
\hline & & (R13) Tunnel face instability \\
\hline & & (R14) Fault zone \\
\hline & & (R15) Squeezing \\
\hline & \multirow{7}{*}{ Safety risk } & (R16) Collapse \\
\hline & & (R17) Rock burst \\
\hline & & (R18) Roof fall \\
\hline & & (R19) Collisions \\
\hline & & (R20) Toxic gas leakage \\
\hline & & (R21) Poor ventilation \\
\hline & & (R22) Fire in tunnel \\
\hline & \multirow{6}{*}{ Health and environment risk } & (R23) Disturbance to the residents near the construction site \\
\hline & & (R24) Physical damage to workers \\
\hline & & (R25) Ecological constraints \\
\hline & & (R26) Surface subsidence \\
\hline & & (R27) Noise \\
\hline & & (R28) Air pollution \\
\hline \multirow{14}{*}{ 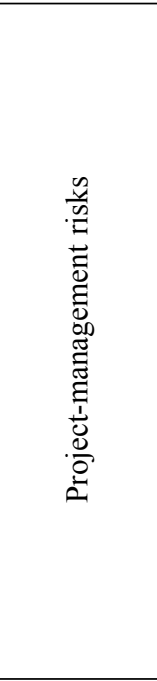 } & \multirow{3}{*}{ Interface risk } & (R29) Interference of different operations \\
\hline & & (R30) Inconsistent schedule in intersections \\
\hline & & (R31) Damage to the foundation of adjacent buildings \\
\hline & \multirow{5}{*}{ Quality risk } & (R32) Inappropriate machine and equipment selection \\
\hline & & (R33) Rough and incomplete construction program \\
\hline & & (R34) Inappropriate material selection \\
\hline & & (R35) Machinery breakdown \\
\hline & & (R36) Poor workmanship \\
\hline & \multirow{2}{*}{ Time risk } & (R37) Poor construction programming \\
\hline & & (R38) Delay of materials supply \\
\hline & \multirow{4}{*}{ Human risk } & (R39) Managerial inability \\
\hline & & (R40) Lack of experienced professional consultants \\
\hline & & (R41) Change of key personnel \\
\hline & & (R42) Workers' strike \\
\hline \multirow{5}{*}{ 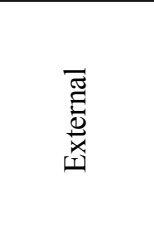 } & \multirow{3}{*}{ Cost risk } & (R43) High tender price \\
\hline & & (R44) Material price escalation \\
\hline & & (R45) Labour cost escalation \\
\hline & Contractual risk & (R46) Delay in contractual progress payment \\
\hline & Financial risk & (R47) Financing difficulties \\
\hline
\end{tabular}


Table 5. Comparison between the results of the proposed model and the conventional model

\begin{tabular}{|c|c|c|c|c|c|c|c|c|}
\hline \multirow{3}{*}{ Risk events } & \multicolumn{4}{|c|}{ Input } & \multicolumn{4}{|c|}{ Output } \\
\hline & \multicolumn{2}{|c|}{ Crisp } & \multicolumn{2}{|c|}{ Fuzzy } & \multicolumn{2}{|c|}{ Conventional method } & \multicolumn{2}{|c|}{ Proposed model } \\
\hline & Probability & Impact & Probability & Impact & Risk & Rank & Risk & Rank \\
\hline (R1) & 3 & 2 & 2.78 & 2.21 & 6 & 30 & 1.56 & 45 \\
\hline (R2) & 2 & 3 & 2.34 & 3.05 & 6 & 30 & 2.56 & 32 \\
\hline (R3) & 2 & 4 & 2.34 & 4.12 & 8 & 23 & 2.89 & 17 \\
\hline (R4) & 1 & 4 & 1.12 & 3.98 & 4 & 44 & 1.57 & 44 \\
\hline (R5) & 2 & 4 & 2.00 & 3.78 & 8 & 23 & 2.50 & 33 \\
\hline (R6) & 2 & 3 & 2.21 & 3.36 & 6 & 30 & 2.75 & 21 \\
\hline (R7) & 2 & 3 & 2.31 & 3.16 & 6 & 30 & 2.69 & 23 \\
\hline (R8) & 1 & 5 & 1.12 & 4.68 & 5 & 42 & 2.31 & 38 \\
\hline (R9) & 1 & 3 & 1.24 & 2.73 & 3 & 46 & 1.53 & 46 \\
\hline (R10) & 3 & 4 & 3.13 & 3.86 & 12 & 7 & 3.53 & 10 \\
\hline (R11) & 4 & 2 & 4.34 & 2.12 & 8 & 23 & 2.65 & 24 \\
\hline (R12) & 3 & 3 & 3.16 & 3.00 & 9 & 19 & 2.61 & 26 \\
\hline (R13) & 2 & 3 & 2.12 & 2.89 & 6 & 30 & 2.38 & 36 \\
\hline (R14) & 3 & 2 & 3.21 & 2.34 & 6 & 30 & 1.99 & 40 \\
\hline (R15) & 2 & 3 & 1.77 & 3.28 & 6 & 30 & 2.24 & 39 \\
\hline (R16) & 3 & 4 & 3.14 & 4.09 & 12 & 7 & 3.67 & 4 \\
\hline (R17) & 1 & 5 & 1.13 & 5.00 & 5 & 42 & 2.59 & 27 \\
\hline (R18) & 3 & 4 & 3.21 & 4.11 & 12 & 7 & 3.67 & 4 \\
\hline (R19) & 5 & 3 & 4.66 & 3.12 & 15 & 4 & 3.67 & 4 \\
\hline (R20) & 5 & 4 & 4.90 & 4.13 & 20 & 1 & 4.34 & 1 \\
\hline (R21) & 3 & 2 & 3.32 & 2.16 & 6 & 30 & 1.91 & 41 \\
\hline (R22) & 2 & 4 & 1.87 & 4.23 & 8 & 23 & 2.59 & 27 \\
\hline (R23) & 3 & 4 & 3.12 & 3.96 & 12 & 7 & 3.60 & 9 \\
\hline (R24) & 5 & 2 & 4.62 & 2.32 & 10 & 16 & 2.88 & 19 \\
\hline (R25) & 3 & 2 & 2.58 & 2.31 & 6 & 30 & 1.68 & 43 \\
\hline (R26) & 3 & 4 & 3.12 & 3.76 & 12 & 7 & 3.44 & 13 \\
\hline (R27) & 4 & 2 & 3.77 & 2.13 & 8 & 23 & 2.41 & 35 \\
\hline (R28) & 3 & 3 & 3.21 & 2.87 & 9 & 19 & 2.57 & 30 \\
\hline (R29) & 2 & 4 & 2.34 & 3.67 & 8 & 23 & 2.89 & 17 \\
\hline (R30) & 2 & 3 & 2.17 & 2.84 & 6 & 30 & 2.32 & 37 \\
\hline (R31) & 3 & 4 & 3.23 & 3.79 & 12 & 7 & 3.46 & 12 \\
\hline (R32) & 4 & 3 & 3.55 & 3.22 & 12 & 7 & 3.16 & 16 \\
\hline (R33) & 1 & 4 & 1.43 & 3.53 & 4 & 44 & 1.82 & 42 \\
\hline (R34) & 2 & 3 & 2.13 & 3.27 & 6 & 30 & 2.65 & 24 \\
\hline (R35) & 5 & 2 & 4.67 & 2.33 & 10 & 16 & 2.88 & 19 \\
\hline (R36) & 2 & 3 & 2.19 & 3.06 & 6 & 30 & 2.57 & 30 \\
\hline (R37) & 3 & 3 & 3.03 & 2.92 & 9 & 19 & 2.47 & 34 \\
\hline (R38) & 4 & 4 & 3.77 & 4.18 & 16 & 2 & 3.71 & 3 \\
\hline (R39) & 2 & 5 & 2.32 & 4.61 & 10 & 16 & 3.25 & 15 \\
\hline (R40) & 1 & 3 & 1.06 & 2.89 & 3 & 46 & 1.41 & 47 \\
\hline (R41) & 2 & 4 & 2.21 & 3.67 & 8 & 23 & 2.75 & 21 \\
\hline (R42) & 3 & 4 & 3.09 & 4.11 & 12 & 7 & 3.67 & 4 \\
\hline (R43) & 3 & 5 & 2.73 & 4.56 & 15 & 4 & 3.35 & 14 \\
\hline (R44) & 3 & 4 & 3.00 & 3.82 & 12 & 7 & 3.49 & 11 \\
\hline (R45) & 3 & 3 & 2.68 & 3.07 & 9 & 19 & 2.58 & 29 \\
\hline (R46) & 4 & 4 & 4.11 & 3.62 & 16 & 2 & 3.66 & 8 \\
\hline (R47) & 3 & 5 & 3.32 & 4.55 & 15 & 4 & 3.77 & 2 \\
\hline
\end{tabular}




\section{Results and discussions}

The main aim of the study is to develop a powerful model for modelling the risks involved in construction projects using a fuzzy rule-based system. In order to investigate the potential application of the proposed model, the PI risk matrix method is applied to calculate the existing risks. For achieving the aim, after listing the risks, a category is determined for both probability and impact based on the scale given in Tables 1 and 2, in which 1 means minimum level and 5 represents the maximum. The risk index is filled in by combining the category information in the two columns or by assigning weights to the categories and using the product of the weights of the probability and impact (Kendrick 2003).

The results of the proposed model are obtained by using the same data applied in the P-I risk matrix. A comparison between the final rankings of the fuzzy proposed model with that of the conventional risk assessment is provided in Table 5. The events with respect to risks are ranked from least to most severe. Compared with the traditional risk assessment, the ranking of the proposed model are clearly different.

It can be seen that the P-I method never assumes values $7,11,13,14,17,18,19,21,22,23$, and 24 . The most significantly debated shortcoming of the traditional risk assessment is that various sets of P and I may generate an identical value for risk index. However, the risk implication may be completely different. This means that the two parameters are assumed to have the same importance. This may result in a bad impact on the results of risk assessment process; so that, the results may be wrong and invalid. As an illustration, take into account two different scenarios having values of 2, 3 and 3,2, for P and I, respectively. Both these failure scenarios will have a risk value of 6 . However, the risk implication of the two scenarios may be significantly different. This is due to the fact that the importance weight of the probability parameter is significantly different from the impact. This problem may impose a waste of time and finance. The merit of using fuzzy rule base is to deal with such failures.

In another case, risks 6 and 41, the output of the proposed model is 2.75 . Hence, two potential causes acquire the same value. However, the P-I risk matrix produces a value of 6 and 8 for risks 6 and 41, respectively. This shows that the ranking of risk 6 in comparison with that of risk 41 has the higher value. This ranking can lead to a waste of time, resources and finances. This problem is prominent when there is a dataset with a high level of uncertainty. This demonstrates that a more reliable, sure, and accurate risk assessment can be yield by using the fuzzy logic.

\section{Conclusions}

Probability-impact (P-I) matrix is a powerful risk analysis tool which is widely used in different aspects of science, management and engineering problems. Risk analysis with aid of P-I risk matrix is the process of prioritizing risks for future analysis by assessing and combining their probability of occurrence and impact. The most important part of analysing the risks imposed by project is to separate the parts of the work that are less risky from the parts that are more risky. Organization can improve the performance of the project by focusing on high-priority risks.

Nevertheless, acquiring precise assessment information on the risk components (i.e. probability of occurrence and the impact) is difficult and even in many situations impossible. For this reason, this paper proposes a fuzzy risk assessment for handling the uncertainty associated with the process of modelling a complex system which allows the risk components and their relative importance to be considered in modelling the risks imposed by the project in a linguistic manner rather than in a precise way. The output of the fuzzy risk model is used for further decision-making in the process of risk management. The potential applications of the proposed model is examined and illustrated with a real world case study. The results demonstrate that the proposed model in comparison with the conventional approach provides a more practical and reliable way for risk assessment. Compared with the conventional approach, the fuzzy model proposed has the following advantages:

1) The relative importance between the risk components $\mathrm{P}$ and $\mathrm{I}$ is taken into account in the process of prioritization of the risks involved in the project, which makes the proposed model more flexible, accurate, practical, and realistic.

2) The assessment is easier to be accomplished because risk components and their relative importance are evaluated by linguistic terms instead of crisp values.

3) Due to the fact that the relative importance between $P$ and I are not exactly the same, different combinations of $\mathrm{P}$ and I produce different risk values. This enables the proposed model to completely evaluate the risks and rank them in a descending order.

\section{References}

Alidoosti, A.; Yazdani, M.; Fouladgar, M. M.; Basiri, M. H. 2012. Risk assessment of critical asset using fuzzy inference system, Risk Management 14: 77-91. http://dx.doi.org/10.1057/rm.2011.19

Aneziris, O. N.; Papazoglou, I. A.; Kallianiotis, D. 2010. Occupational risk of tunnelling construction, Safety Science 48(8): 964-972.

http://dx.doi.org/10.1016/j.ssci.2009.11.003

Aye, Z. Z.; Karki, D.; Schulz, C. 2006. Ground movement prediction and building damage risk-assessment for the deep excavations and tunnelling works in Bangkok Subsoil, in International Symposium on Underground Excavation and Tunnelling, 2-4 February, 2006, Bangkok, Thailand, 281-297.

Beriha, G. S.; Patnaik, B.; Mahapatra, S. S.; Padhee, S. 2012. Assessment of safety performance in Indian industries using fuzzy approach, Expert Systems with Applications 39(3): 3311-3323.

http://dx.doi.org/10.1016/j.eswa.2011.09.018 
Cerić, A.; Marčić, D.; Ivandić, K. 2011 A risk-assessment methodology in tunnelling, Tehnički Vjesnik 18(4): 529_ 536.

Chin, K. S.; Chan, A.; Yang, J. B. 2008. Development of a fuzzy FMEA based product design system, International Journal of Advanced Manufacturing Technology 36: 633649. http://dx.doi.org/10.1007/s00170-006-0898-3

Dikmen, I.; Birgonul, M. T.; Han, S. 2007. Using fuzzy risk assessment to rate cost overrun risk in international construction projects, International Journal of Project Management 25(5): 494-505. http://dx.doi.org/10.1016/j.ijproman.2006.12.002

Einstein, H. H. 1996. Risk and risk analysis in rock engineering, Tunnelling and Underground Space Technology 11(2): 141155. http://dx.doi.org/10.1016/0886-7798(96)00014-4

Elsayed, T. 2009. Fuzzy inference system for the risk assessment of liquefied natural gas carriers during loading/offloading at terminals, Applied Ocean Research 31(3): 179 185. http://dx.doi.org/10.1016/j.apor.2009.08.004

Eskesen, S. D.; Tengborg, P.; Kampmann, J.; Veicherts, T. H. 2004. Guidelines for tunnelling risk management: International Tunnelling Association, Working Group No. 2, Tunnelling and Underground Space Technology 19(3): 217-237. http://dx.doi.org/10.1016/j.tust.2004.01.001

Fouladgar, M. M.; Yazdani-Chamzini, A.; Lashgari, A.; Zavadskas, E. K.; Turskis, Z. 2012a. Maintenance strategy selection using AHP and COPRAS under fuzzy environment, International Journal of Strategic Property Management 16(1): 85-104. http://dx.doi.org/10.3846/1648715X.2012.666657

Fouladgar, M. M.; Yazdani-Chamzini, A.; Zavadskas, E. K. 2011. An integrated model for prioritizing strategies of the Iranian mining sector, Technological and Economic Development of Economy 17(3): 459-483. http://dx.doi.org/10.3846/20294913.2011.603173

Fouladgar, M. M.; Yazdani-Chamzini, A.; Zavadskas, E. K. 2012b. Risk evaluation of tunnelling projects, Archives of Civil and Mechanical Engineering 12: 1-12. http://dx.doi.org/10.1016/j.acme.2012.03.008

Fouladgar, M. M.; Yazdani-Chamzini, A.; Zavadskas, E. K.; Moini, S. H. H. 2012d. A new hybrid model for evaluating the working strategies: case study of construction company, Technological and Economic Development of Economy 18(1): 164-188. http://dx.doi.org/10.3846/20294913.2012.667270

Fouladgar, M. M.; Yazdani-Chamzini, A.; Zavadskas, E. K.; Yakhchali, S. H.; Ghasempourabadi, M. H. 2012c. Project portfolio selection using fuzzy AHP and VIKOR techniques, Transformations in Business \& Economics 11(1): 213-231.

Gattinoni, P.; Scesi, L.; Terrana, S. 2008. Hydrogeological risk analysis for tunnelling in anisotropic rock masses, in World Tunnel Congress 2008 - Underground Facilities for Better Environment and Safety, 22-24 September, 2008, Agra, India, 1735-1747.

Ghasemi, E.; Ataei, M. 2013. Application of fuzzy logic for predicting roof fall rate in coal mines, Neural Computing and Applications 22(1): 311-321. http://dx.doi.org/10.1007/s00521-012-0819-3

Ghorbani, M.; Sharifzadeh, M.; Yasrobi, S.; Daiyan, M. 2012. Geotechnical, structural and geodetic measurements for conventional tunnelling hazards in urban areas - the case of Niayesh road tunnel project, Tunnelling and Underground Space Technology 31: 1-8. http://dx.doi.org/10.1016/j.tust.2012.02.009

Gupta, M.; Knopf, G.; Nikiforuk, P. 1988. Sinusoidal-based cognitive mapping functions, in Yamakawa, T.; Gupta, M. M. (Eds). Fuzzy Logic in Knowledge-based Systems. Amsterdam: Elsevier, 69-92.
Gürcanli, G. E.; Müngen, U. 2009. An occupational safety risk analysis method at construction sites using fuzzy sets, International Journal of Industrial Ergonomics 39(2): 371387. http://dx.doi.org/10.1016/j.ergon.2008.10.006

Hamidi, J. K.; Shahriar, K.; Rezai, B.; Rostami, J. 2010. Performance prediction of hard rock TBM using Rock Mass Rating (RMR) system, Tunnelling and Underground Space Technology 25(4): 333-345. http://dx.doi.org/10.1016/j.tust.2010.01.008

Heldman, K.; Baca, C.; Jansen, P. 2007. PMP: Project management professional exam study guide. $2^{\text {nd }}$ ed. New York: Wiley Publishing. 696 p.

Holicky, M. 2008. Risk assessment and optimization of road tunnels, Reliability \& Risk Analysis: Theory \& Applications 4(1): 52-59.

Hong, E. S.; Lee, I. M.; Shin, H. S.; Nam, S. W.; Kong, J. S. 2009. Quantitative risk evaluation based on event tree analysis technique: application to the design of shield TBM, Tunnelling and Underground Space Technology 24(3): 269-277.

http://dx.doi.org/10.1016/j.tust.2008.09.004

Huang, H.; Chen, L. 2006. Risk analysis of building structure due to shield tunnelling in urban area, in $\mathrm{Zhu}, \mathrm{H}$; Zhang, F.; Chin, C.-T.; Zhang, D. (Eds). Underground Construction and Ground Movement. American Society of Civil Engineers, USA, 150-157. http://dx.doi.org/10.1061/40867(199)17

Jamshidi, A.; Yazdani-Chamzini, A.; Yakhchali, S. H.; Khaleghi, S. 2013. Developing a new fuzzy inference system for pipeline risk assessment, Journal of Loss Prevention in the Process Industries 26(1): 197-208. http://dx.doi.org/10.1016/j.jlp.2012.10.010

Karimi, I.; Hüllermeier, E. 2007. Risk assessment system of natural hazards: a new approach based on fuzzy probability, Fuzzy Set Systems 158(9): 987-999. http://dx.doi.org/10.1016/j.fss.2006.12.013

Kendrick, T. 2003. Identifying and managing project risk: essential tools for failure-proofing your project. American Management Association. 368 p.

Khalil, M.; Abdou, M. A.; Mansour, M. S.; Farag, H. A.; Ossman, M. E. 2012. A cascaded fuzzy-LOPA risk assessment model applied in natural gas industry, Journal of Loss Prevention in the Process Industries 25(6): 877-882. http://dx.doi.org/10.1016/j.jlp.2012.04.010

Khazaeni, G.; Khanzadi, M.; Afshar, A. 2012. Fuzzy adaptive decision making model for selection balanced risk allocation, International Journal of Project Management 30(4): $511-522$. http://dx.doi.org/10.1016/j.ijproman.2011.10.003

Lashgari, A.; Fouladgar, M. M.; Yazdani-Chamzini, A.; Skibniewski, M. J. 2011. Using an integrated model for shaft sinking method selection, Journal of Civil Engineering and Management 17(4): 569-580. http://dx.doi.org/10.3846/13923730.2011.628687

Lashgari, A.; Yazdani-Chamzini, A.; Fouladgar, M. M.; Zavadskas, E. K.; Shafiee, S.; Abbate, N. 2012. Equipment selection using fuzzy multi criteria decision making model: key study of Gole Gohar Iron Min, Inzinerine Ekonomi$k a$-Engineering Economics 23(2): 125-136.

Liu, H.-T.; Tsai, Y.-L. 2012. A fuzzy risk assessment approach for occupational hazards in the construction industry, Safety Science 50(4): 1067-1078. http://dx.doi.org/10.1016/j.ssci.2011.11.021

Markowski, A. S.; Mannan, M. S. 2009. Fuzzy logic for piping risk assessment (pfLOPA), Journal of Loss Prevention in the Process Industries 22(6): 921-927. http://dx.doi.org/10.1016/j.jlp.2009.06.011

Masters, T. 1995. Advanced algorithms for neural networks: a $C++$ Sourcebook. New York: Wiley. 448 p. 
MathWorks. 2012. Foundations of fuzzy logic. Fuzzy logic toolbox [online], [cited 0510 2012]. Available from Internet: http://www.mathworks.com.

Merna, T.; Al-Thani, F. F. 2005. Corporate risk management: An organisational perspective. London: John Wiley and Sons Ltd. 270 p.

Moergeli, A. 2004. Risk management in tunnelling - occupational safety + health plans for drill and blast and tunnel boring machines, in Proc. of the North American Tunneling Conference, 2004, Atlanta, Georgia, USA, 153163.

Ngai, E. W. T.; Wat, F. K. T. 2005. Fuzzy decision support system for risk analysis in e-commerce development, Decision Support Systems 40(2): 235-255. http://dx.doi.org/10.1016/j.dss.2003.12.002

Nieto-Morote, A.; Ruz-Vila, F. 2011. A fuzzy approach to construction project risk assessment, International Journal of Project Management 29(2): 220-231. http://dx.doi.org/10.1016/j.ijproman.2010.02.002

Parker, H. W. 2005. International Tunnelling Association (ITA) and risk. George Fox Seminar.

Pillay, A.; Wang, J. 2003. Chapter 6. Risk assessment using fuzzy set approach, Elsevier Ocean Engineering Series 7: 117-147.

Razani, M.; Yazdani-Chamzini, A.; Yakhchali, S. H. 2013. A novel fuzzy inference system for predicting roof fall rate in underground coal mines, Safety Science 55: 26-33. http://dx.doi.org/10.1016/j.ssci.2012.11.008

Rehana, S.; Mujumdar, P. P. 2009. An imprecise fuzzy risk approach for water quality management of a river system, Journal of Environmental Management 90(11): 36533664. http://dx.doi.org/10.1016/j.jenvman.2009.07.007

Reilly, J. J. 2005. Cost estimating and risk management for underground projects, in Proc. of International Tunneling Association Conference, May, 2005, Istanbul, Turkey, $1-9$.

Reilly, J. J.; Brown, J. 2004. Management and control of cost and risk for tunnelling and infrastructure projects, in Proc. of International Tunneling Conference, May, 2004, Singapore, 1-8.

Richards, D. P.; Nilsen, B. 2007. Geotechnical risk management for tunnelling beneath open water, in Barták, J.; Hrdina, I.; Romancov, G.; Zlámal, J. (Eds). Underground Space - the 4th Dimension of Metropolises. London: Taylor \& Francis, 1585-1590.

Sahel Consulting Eng. 2007. Engineering geological investigations along the Zagros Long Tunnel alignment. Report No: SCE 2026 UNGR SIT EG RP 002 D1. 58 p.

Salvucci, F. 2003. The 'Big Dig' of Boston. Massachusetts: lessons to learn. T\&T North America, USA. Presentation materials.

Shahriar, A.; Sadiq, R.; Tesfamariam, S. 2012. Risk analysis for oil \& gas pipelines: a sustainability assessment approach using fuzzy based bow-tie analysis, Journal of Loss Prevention in the Process Industries 25(3): 505-523. http://dx.doi.org/10.1016/j.jlp.2011.12.007

Sousa, R. L.; Einstein, H. H. 2012. Risk analysis during tunnel construction using Bayesian Networks: Porto Metro case study, Tunnelling and Underground Space Technology 27(1): 86-100. http://dx.doi.org/10.1016/j.tust.2011.07.003

Sumathi, S.; Paneerselvam, S. 2010. Computational intelligence paradigms: theory \& applications using MATLAB. London: Taylor \& Francis. 851 p.
Tay, K. M.; Lim, C. P. 2006. Fuzzy FMEA with a guided rules reduction system for prioritization of failures, International Journal of Quality \& Reliability Management 23(8): 10471066. http://dx.doi.org/10.1108/02656710610688202

Thomas, A. H.; Banyai, J. P. 2007. Risk management of the construction of tunnels using Tunnel Boring Machines (TBMs), in Barták, J.; Hrdina, I.; Romancov, G.; Zlámal, J. (Eds). Underground Space - the 4th Dimension of Metropolises. London: Taylor \& Francis, 1613-1618.

Wang, L.-X. 1994. Adaptive fuzzy systems and control - Design and stability analysis. New York: Prentice Hall. 232 p.

Wang, L.-X. 1997. A course in fuzzy systems and control. New York: Prentice Hall, Upper Saddle River. 424 p.

Wong, B. K.; Monaco, J. A. 1995. A bibliography of expert system applications for business (1984-1992), European Journal of Operational Research 85(2): 416-432. http://dx.doi.org/10.1016/0377-2217(95)00047-T

Wulan, M.; Petrovic, D. 2012. A fuzzy logic based system for risk analysis and evaluation within enterprise collaborations, Computers in Industry 63(8): 739-748. http://dx.doi.org/10.1016/j.compind.2012.08.012

Xie, M. 2003. Fundamentals of robotics: linking perception to action. London: World Scientific Publishing Co Ltd. $716 \mathrm{p}$.

Xu, Y.; Yeung, J. F. Y.; Chan, A. P. C.; Chan, D. W. M.; Wang, S. Q.; Ke, Y. 2010. Developing a risk assessment model for PPP projects in China - a fuzzy synthetic evaluation approach, Automation in Construction 19(7): 929943. http://dx.doi.org/10.1016/j.autcon.2010.06.006

Yazdani, M.; Alidoosti, A.; Zavadskas, E. K. 2011. Risk analysis of critical infrastructures using fuzzy Copras, Ekonomska istraživanja - Economics Research 24(4): 27-40.

Yazdani-Chamzini, A.; Yakhchali, S. H. 2012. Tunnel Boring Machine (TBM) selection using fuzzy multicriteria decision making methods, Tunnelling and Underground Space Technology 30: 194-204. http://dx.doi.org/10.1016/j.tust.2012.02.021

Yazdani-Chamzini, A.; Yakhchali, S. H.; Mahmoodian, M. 2013. Risk ranking of tunnel construction projects by using the ELECTRE technique under a fuzzy environment, International Journal of Management Science and Engineering Management 8(1): 1-14.

Yazdani-Chamzini, A.; Yakhchali, S. H.; Volungevičienė, D.; Zavadskas, E. K. 2012. Forecasting gold price changes by using adaptive network fuzzy inference system, Journal of Business Economics and Management 13(5): 994 1010. http://dx.doi.org/10.3846/16111699.2012.683808

Yoo, C.; Kim, J. H. 2003. A web-based tunneling-induced building/utility damage assessment system: TURISK, Tunnelling and Underground Space Technology 18(5): 497-511. http://dx.doi.org/10.1016/S0886-7798(03)00067-1

Yucel, G.; Cebi, S.; Hoege, B.; Ozok, A. F. 2012. A fuzzy risk assessment model for hospital information system implementation, Expert Systems with Applications 39(1): 1211-1218.

Zadeh, L. A. 1965. Fuzzy sets, Information and Control 8(3): 338-353. http://dx.doi.org/10.1016/S0019-9958(65)90241-X

Zadeh, L. A. 1992. The calculus of fuzzy if-then rules, in Proc. of the Theorie und Praxis, Fuzzy Logik, 1992, 84-94.

Zou, P. X. W.; Li, J. 2010. Risk identification and assessment in subway projects: case study of Nanjing Subway Line 2, Construction Management and Economics 28(12): 12191238. http://dx.doi.org/10.1080/01446193.2010.519781

Abdolreza YAZDANI-CHAMZINI. Master of Science in the Department of Mining Engineering, research assistant of Tehran University, Tehran-Iran. Author of more than 46 research papers. In 2011, he graduated from the Science and Engineering Faculty at Tarbiat Modares University, Tehran-Iran. His research interests include decision making, forecasting, modelling, and optimization. 